Article

\title{
Influence of Sustainable Development by Tourists' Place Emotion: Analysis of the Multiply Mediating Effect of Attitude
}

\author{
Yuangang Zhang ${ }^{1,2}$ and Lijuan Wang ${ }^{1, *}$ \\ 1 Faculty of International Tourism and Management, City University of Macao, Macau, China; \\ T16092100085@cityu.mo \\ 2 Academy of Economics and Management, Huangshan University, Huangshan 245021, China \\ * Correspondence: T17092105137@cityu.mo
}

Received: 9 February 2019; Accepted: 3 March 2019; Published: 6 March 2019 updates

\begin{abstract}
Place emotion is an important factor in studying the behavioral intention of tourists. Based on the planning behavior theory and goal-oriented behavior model, this article combines the actual situation of rural tourist, expands the behavioral theory, and constructs the tourist behavior of place emotion. This paper takes the World Cultural Heritage Sites Xidi and Hongcun as research cases and uses Structural Equation Modeling (SEM) research methods. The results indicate that the constructed behavior intention of tourists traveling in rural areas gives a good explanation and goodness of fit. The influence of place emotion on behavioral intention is stronger than attitude, subjective norm, and perceptual behavior control. Through multiple mediation analysis, attitudes have partial mediating effects on place emotions, perceptual behavior control, and subjective norms, and the place emotion has the most significant among the indirect effects, followed by subjective norms and perceptual behavior control. The results provide reliable advice for the sustainable development of rural tourism.
\end{abstract}

Keywords: place emotion; behavior intention; model reconstruction; multiple mediation; rural tourists

\section{Introduction}

Since the end of the 20th century, rural tourism has developed rapidly in China and has gradually become a popular tourist product type. In the process of promoting rural revitalization, the state promulgated the Number 1 Document of "Central Committee of the Communist Party of China on the Implementation of Rural Revitalization", which objectively promoted the development of rural tourism. The development of rural tourism as one of the important ways to promote the development and revitalization of rural areas has reached the consensus of scholars [1-6].

Rural tourism has always been a focus of scholars at home and abroad. The research content mainly focuses on tourism preferences, behavioral characteristics, consumption characteristics, travel factors, satisfaction, and loyalty of rural tourists $[7,8]$. After reading these researches, we found that rural tourists present a certain spatial regularity and also attract groups of urban residents, which include elderly couples and families with children. Among the tourist group, the behavioral intention characteristics and influencing factors of rural tourists attract scholars' attention.

For China, rural development is one of the key issues to ensure the overall social operation; the strategic significance of rural development is significant and needs to be studied. However, the relevant researches of foreign developed countries cannot be rigidly used under the special national conditions of China; it is urgent to study the localization of China's national conditions. Research on rural development has always been the focus of academic research; scholars have explored this topic from different theoretical perspectives and disciplines. There are also interdisciplinary 
studies combining geography and sociology. From the perspective of the research results of the tourism industry, the research on rural tourism has promoted the development of rural areas. In recent years, China has developed rural tourism as an important way of promoting rural revitalization. The rural tourist, as a core element to promote the development of rural tourism, has been receiving continuous attention from scholars. However, in general, the current domestic research on rural tourists is still relatively lack of scientific division framework, and systematic theoretical deepening. However, rural tourists are the core elements of rural tourism development. Chinese scholars have relatively little theoretical discussion on the tourism behavior of rural tourists. Based on these reasons, this paper attempts to construct the theoretical framework of rural tourists' behavior and provides the development reference for rural tourism in China $[9,10]$.

In the study of tourist behavioral intentions, both domestic and foreign, the Theory of Planned Behavior (TPB) is a relatively mature theoretical framework. In recent years, some scholars have applied the goal-oriented behavior model (MGB) to research into the behavioral intentions of tourists. These two theoretical frameworks have their own advantages in analyzing the behavioral intentions of different types of tourists [11-13]. Some authors have questioned the application of the TPB [11,14,15]. In fact, Ajzen, the founder of the TPB, points out that the theory is a broad range and instructional framework. When scholars use the TPB to study different behaviors, it is necessary to add some new variables to the original model and therefore enhance the theoretical explanation [16].

Place emotion is an important factor for studying tourists, and a model has been constructed from the perspective of place emotional factors [17]. By studying the current research literature, defining the basic theories, and confirming the construction variables and the model framework, this paper proposes a model which links choice of tourism destination with place emotion. The development of rural tourism is one of the significant approaches to revitalize the countryside. As an essential part of rural tourism, rural tourists have always appealed to researchers. This paper takes the villages of Xidi and Hongcun, Anhui Province, China, as case studies, which are both World Cultural Heritage Sites, and reconstructs rural tourists' behavior using an intention model. The reconstruction model can provide some reference for the recreational behavior of rural tourists.

\section{Theoretical Discussion and Model Construction}

\subsection{Expansion of Place Emotional Factors}

From the perspective of social psychology, place is not a purely spatial concept, but is also a social construction that is endued with special meanings and values by individuals and groups [18]. For tourist attractions, when tourists attach a specific value in people-place interaction and form positive emotional bond with a scenic spot, this will generate an emotional attachment between individuals and the scenic spot (called 'place attachment') [18,19]. Place emotion is an important concept in the field of environmental psychology, and represents the emotional bond and psychological identity between individuals and specific environments, which reflects the people-place attachment relationship caused by people's emotional input at the place [20]. As there is no obvious difference between place attachment and place emotions, place attachment has often been used to refer to place emotion in previous studies $[18,21]$.

The attitudes and behaviors of individuals or groups are easily influenced by the emotions, memories, and values that are attached to a place [22]. In current studies, some researchers add the variable of emotion and emotional attachment relationship to the TPB model, which will reconstruct and expand the theory, and can also effectively enhance the interpretation of the relevant behavioral decision-making process $[13,18]$. Especially in the behavior situation of leisure travel and safe behavior, emotional factors play an important role. The emotional attachment relationship not only expands the theoretical model of TPB, but also enhances the validity of the model's interpretation and the prediction of individual behavior [23]. 
Tourism consumption shows obvious symbolic consumption characteristics. Tourists express self-image, self-worth, and social identity through tourism activities [24], while tourists' place emotions play an extremely vital role in those activities [18,25]. Previous studies have found that the emotional connection between tourists and the destinations they travel to has an influence on the payment attitudes and resource protection attitudes of tourists, and thus produces behavioral intentions [13]. Additionally, the psychological identity and emotional relationship between a tourist and a destination (scenic area) has a significant positive effect on the tourist's intention (such as willingness to revisit, willingness to recommend, and willingness to pay) [26].

H1. The influence of place emotion.

H1a. Place emotion has a significant effect on rural tourist attitudes.

H1b. Place emotion has a significant effect on rural tourist behavioral intentions.

\subsection{Behavioral Reconstruction Model}

Ajzen, the founder of the TPB, points out that the cognition of social norms and the motivation to be consistent with others' opinions have a significant effect on individuals' behavioral intentions. Additionally, Azjen acknowledges the "social rationality" in the individual that plays an important role in the behavioral decision-making process. On the basis of Ajzen's theory, many researchers believe that personal subjective norms and attitudes are not independent predictors. However, others' opinions and sharing criteria in social relationships can influence the overall attitude of individuals in implementing specific behaviors, and can therefore indirectly drive individual implementing specific behavior intention $[13,16,27-29]$.

Han used the TPB to study tourists' willingness to choose green hotels and compared the explanatory power of the TPB with the Theory of Reasoned Action (TRA). He found that in the model of the TPB, attitude, subjective norms, and perceived behavioral control all have a significant positive effect on tourists' intention to choose green hotel, and that the subjective norm is an intermediary that indirectly influences behavioral intention through the intermediary role of attitude [27]. Similar to this research, scholars can obtain subjective norms and behavior control cognitions through the attitude reinvention of the TPB model. Positive attitudes are not the only factor that directly affects the behavioral intentions of consumers, but subjective norms, perceptual behavior control, and consumer value all play an intermediary role; subjective norms and perceptual behavior control are stronger, and consumers are more likely to form a positive attitude towards tourism and then form a positive behavioral intention [28].

H2. Effect of subjective normative dimensions.

H2a. Subjective norms have a significant effect on attitudes.

H2b. Subjective norms have a significant effect on rural tourism behavioral intentions.

H3. Effect of the perceived behavioral control dimension.

H3a. Perceived behavior control cognition has a significant effect on attitude.

H3b. Perceived behavioral control cognition has a significant effect on rural tourism behavioral intentions.

H4. Attitude has a significant effect on rural tourism behavioral intentions.

\subsection{Behavioral Attitude as a Mediating Role}

Ajzen and Fishbein, who pioneered the TPB model, have stated that the individual's acceptance of social norms and the herd motivations consistent with others' opinions have a significant influence on individual behavioral intentions [16]. They have also stated that "social rationality" plays an important role in the substantive decision-making process of individuals. 
In reviews of previous research, some studies have proved this concept $[13,15,28,29]$. In their research into the behavior of tourists who choose tourism destination-specific diets, Ryu and Jang improved the rational behavior theory found that subjective norms and attitudes are not independent predictors of driving behaviors; rather, they are interrelated. Additionally, they discovered that an individual's behavioral attitudes improved with the subjective norms and that the explanatory ability of the TRA model for behavioral intention significantly improved [28]. Furthermore, through the reformation of the TPB model, subjective norms and behavioral control cognitions had an indirect effect on behavioral intentions by attitudes [27].

When studying the relationship between attitude and behavioral intention, scholars have realized that previous research was not able to reveal the causal relationship between them [30]. Initially, scholars applied rational behavior theory to emphasize the direct influence of attitude on behavioral intentions; however, more and more empirical studies have found that the explanatory ability of attitudes for behavioral intentions do not reach the ideal state as they expected. In other words, attitudes as an intermediary variable are only theoretically used to explain the influence of subjective norms and behavioral control cognition on the intentions of tourists. However, there is still a certain gap between empirical analysis and satisfactory results [31-35]. New variables are introduced for different research scenarios to bridge this gap. It should also be considered to add new variables to the model to improve its predictive ability $[13,16,18]$.

Therefore, we put forward the following additional hypotheses:

H5. Attitude has a significant influence on the desires and behavioral intentions of rural tourists, and has a mediating influence on subjective norms, behavioral control cognition, and space emotions of rural tourism behavioral intentions.

H5a. Attitude has a mediating influence on the behavioral control cognition of rural tourism behavioral intentions.

H5b. Attitude has a mediating influence on subjective norms of rural tourism behavioral intentions.

H5c. Attitude has a mediating influence on the space emotions of rural tourism behavioral intentions.

Based on the above theoretical speculation and literature research, this article incorporates space emotions and expands the rational elements contained with attitude in the TPB and MGB models. The model can be reconstructed and revised from the "individual rationality" to the "collective rationality" and "social rationality". A conceptual model of the influence on rural tourists' behavioral intentions is shown in Figure 1.

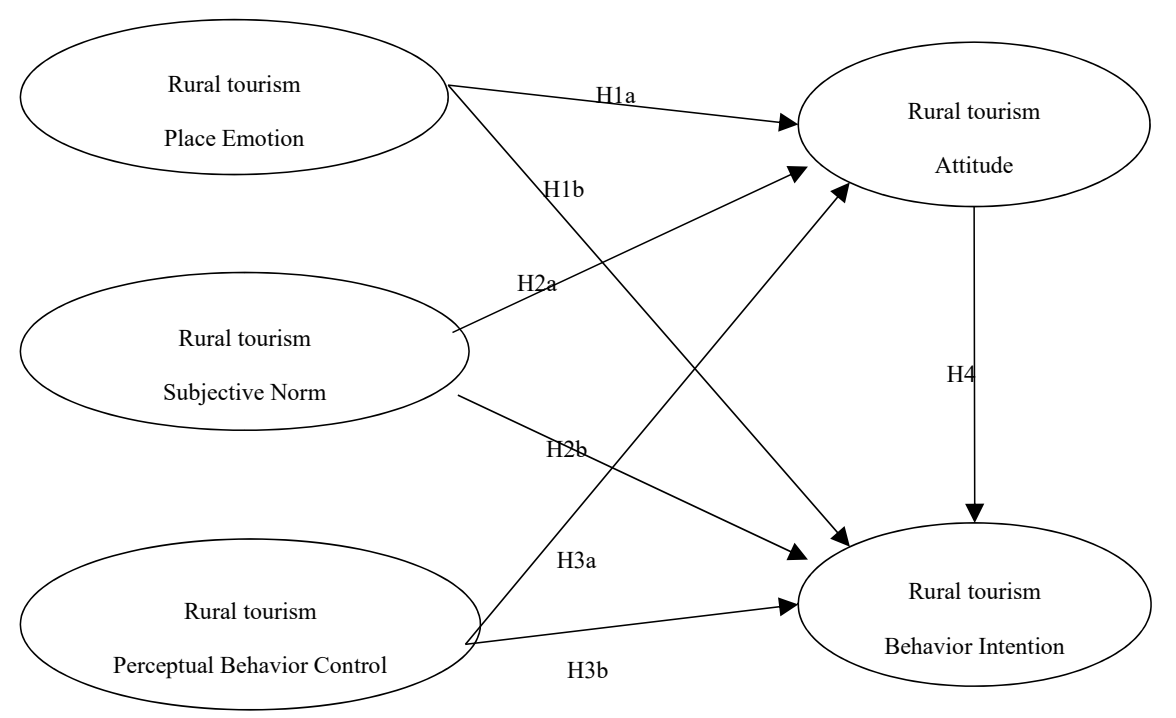

Figure 1. Conceptual model. 


\section{Data and Sample Analysis}

\subsection{Questionnaire Design}

The questionnaire includes basic information of tourists, demographic characteristics, and questionnaire scale. The content of the questionnaire scale consists of the individual's attitude towards rural tourism, tourism motivation, space emotion, subjective norms, perceptual behavior control, and behavioral intention. This paper only extracted options related to rural tourism behavior, and combined domestic and foreign research on rural tourism behavior. A Likert's seven-point scale was used, which consists of a value of 1 to 7 (strongly disagree is 1 , strongly agree is 7 ). The seven questions of space emotion refer to the scales designed by Kyle and Zhang et al. [13,25]; the four questions of subjective norms refer to the design of Lin and Sparks [14,15]; the five questions of perceptual behavior control refer to the scales designed by Han and Sparks [15,27]; the five questions of rural tourism attitude refer to Sparks and Zhang et al. [13,15]; and the five questions of behavioral intention refer to the scales designed by Fielding and Han [27,29]. The particular measurement of each variable and their sources are shown in Table 1.

Table 1. The resource of scale.

\begin{tabular}{|c|c|c|}
\hline Variable & Item & Resource \\
\hline Place emotion (PE) & $\begin{array}{l}\text { I identify strongly with rural tourism (PE1) } \\
\text { Rural tourism means a lot to me (PE2) } \\
\text { For me, rural tourism cannot be replaced (PE3) } \\
\text { I get much satisfaction out of rural tourism (PE4) } \\
\text { I actively take part in rural tourism (PE5) } \\
\text { I am very interested in rural tourism (EI6) }\end{array}$ & {$[13,25]$} \\
\hline Perceived behavioral control (PBC) & $\begin{array}{l}\text { It's easy for me to participate in rural tourism (PBC1) } \\
\text { I feel there is nothing that prevents me from taking a rural } \\
\text { tourism (PBC2) } \\
\text { If I want, I can take part in rural tourism (PBC3) }\end{array}$ & {$[15,27]$} \\
\hline Subjective norm (SN) & $\begin{array}{l}\text { Family members think that it is meaningful to take part in } \\
\text { rural tourism (SN1) } \\
\text { Most people prefer that I should take part in rural } \\
\text { tourism (SN2) } \\
\text { Friends have recommended I take part in rural tourism (SN3) } \\
\text { Friends think that it is meaningful to take part in rural } \\
\text { tourism (SN4) }\end{array}$ & {$[14,15]$} \\
\hline Attitude (ATT) & $\begin{array}{l}\text { It is pleasant to participate in rural tourism activities (ATT1) } \\
\text { It is meaningful to participate in rural tourism } \\
\text { activities (ATT2) } \\
\text { Rural tourism can create beautiful memories (ATT3) } \\
\text { Rural tourism can increase vision (ATT4) }\end{array}$ & {$[13,15]$} \\
\hline Behavior intention (BI) & $\begin{array}{l}\text { I will recommend others to take part in rural tourism (BI1) } \\
\text { I am willing to take part in rural tourism again (BI2) } \\
\text { I will take part in rural tourism because of local special } \\
\text { activities (BI3) }\end{array}$ & {$[27,29]$} \\
\hline
\end{tabular}

\subsection{Data}

Targets were selected from China's beautiful rural tourism destinations in order to make the sample representative; the selected targets are Xidi and Hongcun, Yixian County, Huangshan City, Anhui Province, China. Xidi and Hongcun are World Cultural Heritage Sites and also national 5A tourist attractions. (The national 5A tourist attraction is an evaluation standard of China. It refers to the quality level of China's tourist attractions. It is divided into five levels, from high to low: AAAAA, AAAA, AAA, AA, and A. Grade 5A is the highest level of China's tourist attractions, representing the level of China's world-class boutique tourist attractions.) They are the two most representative ancient villages in southern Anhui Province. They are famous for their rural landscapes of idyllic beauty, geographical layout of well-preserved villages, exquisite domestic architecture of 
Hui characteristic, as well as their colorful life of historical and cultural attractions, also known as the "village in the painting".

Questionnaires were distributed in the above two regions from 12 to 21 October 2018. There were two teams, each with two teachers and 13 students; a total of 15 persons in one group. The rural tourism industry in the above-mentioned regions has developed well, with a large number of tourists, with high typicality and representativeness. The questionnaires were collected by convenience sampling. Because the content of the questionnaire contains local emotions, perceptual behavior control and subjective norms, visitors could not always easily understand the meaning of the sentence when they answered. The members of the research team needed to explain the contents of the questionnaire in detail when the tourists filled in the questionnaire to ensure that the participants fully understood the contents of the questionnaire. Then, they were filled in to ensure the reliability and validity of the questionnaire. During this period, 700 questionnaires were distributed, 685 of which were received and 650 of which were valid. A total of 350 questionnaires were distributed in Yixian County, 345 of which were returned and 321 of which were valid. A total of 350 questionnaires were issued in Xidi, 340 of which were returned and 329 of which were valid.

For the valid questionnaires, the total number of female respondents was 345 and the number of male respondents was 305. The respondents were mostly between 30 and 50 years old; a total of 109 people were 21-30 years old, 255 people $31-40$ years old, 122 people $41-50$ years old, 88 people 51-60 years old, 55 people 61-70 years old, and 21 people with other ages. An analysis of the educational level of respondents showed that 186 people had a high school education and below, 245 respondents had a college education, and 219 respondents had a bachelor's degree or above. The respondents' occupations were mostly professional/educational related, civil service related, and students, who accounted for 395 of the respondents, see Table 2.

Table 2. Profiles of respondents.

\begin{tabular}{|c|c|c|c|c|c|c|c|}
\hline Demographics & Level & Frequency & Percent (\%) & Demographics & Level & Frequency & Percent (\%) \\
\hline \multirow[b]{2}{*}{ Gender } & Male & 305 & 46.9 & Occupation & Civil servant & 105 & 16.2 \\
\hline & Female & 345 & 53.1 & & $\begin{array}{c}\text { Enterprise or } \\
\text { institution staff }\end{array}$ & 85 & 13.1 \\
\hline \multirow{4}{*}{ Age } & $<20$ & 18 & 2.8 & & $\begin{array}{l}\text { Professional or } \\
\text { educational staff }\end{array}$ & 195 & 30.0 \\
\hline & $20-30$ & 109 & 16.8 & & Clerks & 87 & 13.4 \\
\hline & $31-40$ & 255 & 39.2 & & Students & 95 & 14.6 \\
\hline & $>40$ & 268 & 41.2 & & Others & 83 & 12.7 \\
\hline \multirow{4}{*}{ Education } & $\begin{array}{l}\text { High school } \\
\text { or below }\end{array}$ & 186 & 28.6 & \multirow{2}{*}{$\begin{array}{l}\text { Frequency of } \\
\text { taking trip }\end{array}$} & Once & 536 & 82.5 \\
\hline & College & 245 & 37.7 & & Twice $\geq$ ) & 114 & 17.5 \\
\hline & University & 157 & 24.2 & \multirow{5}{*}{ Nature of trip } & Package tour & 138 & 21.2 \\
\hline & $\begin{array}{l}\text { Postgraduate } \\
\text { or above }\end{array}$ & 62 & 9.5 & & $\begin{array}{l}\text { Travel with family } \\
\text { and friends }\end{array}$ & 319 & 49.1 \\
\hline \multirow{3}{*}{ Length of trip } & One day & 445 & 68.5 & & Individual & 76 & 11.7 \\
\hline & 2-3 days & 169 & 26.0 & & $\begin{array}{l}\text { Organized by } \\
\text { enterprises }\end{array}$ & 105 & 16.2 \\
\hline & $>3$ days & 36 & 5.5 & & Others & 12 & 1.8 \\
\hline
\end{tabular}

\section{Results}

\subsection{Common Method Variation Test}

In this paper, a rural tourist behavior intention model was designed as a multivariate analysis. In the process of Structural Equation Model (SEM) analysis, we needed to test the collected data for the existence of Common Method Variation (CMV). The related expansion between variables may not be able to display the true situation between variables. In fact, the respondents' replies in the 
questionnaire led to the correlated expansion between the measured variables due to the classified information, that is, homologous bias results [36].

Podsakoff recommends using William's Unmeasured Latent Method Construct (ULMC) method to verify CMV [37], which is more rigorous than the Hamman test and the single factor Confirmatory Factor Analysis (CFA) test. This paper used ULMC to for testing. Firstly, we assumed that $\mathrm{H} 0=\mathrm{CMV}$ has no influence on the parameters estimated in the model. The result was $\chi^{2}=105.219, \mathrm{CMIN}=3.859$, $p=0.156, p>0.05$. The Hypothesis is supportive, indicating that the model constructed in this paper is not under the influence of CMV. The collected data did not have measurement errors; thus, there is no need to consider the impact of CMV.

\subsection{Model Analysis}

In order to ensure the reliability and validity of the study, we used the Maximum likelihood (ML) of the Amos 21.0 (IBM, Armonk, NY, USA) software to determine the CFA, judging whether the model construction met the requirement by the fitness index. The question item with a factor load ( $\lambda$ value) less than the standard value of 0.6 and with the highest relevant chi-square value was deleted; after deleting, there were 24 items used for studying. The deviation values of the 24 items range from -9.96 to 0.195 and the kurtosis values range from -0.745 to 1.665 . These items matched an absolute value of skewness coefficient of less than three and an absolute value of the kurtosis coefficient of less than 10. This was consistent with the normal distribution of item data proposed by Kline [38].

The factor loading (standardization) range of each item was $0.637 \sim 0.959$, and the result was significant. The Squared Multiple Correlation (SMC) was between 0.447 0.919; this is greater than 0.36 , that is, it reached the ideal condition. The Cronbach's $\alpha$ values of PE, PBC, SN, ATT, BI were, respectively, $0.889,0.812,0.818,0.916,0.918$, and 0.861 , i.e., higher than 0.7 , indicating that each item has a good internal consistency. The Combined Reliability (CR) values were $0.892,0.820,0.822,0.920$, 0.919 , and 0.867 , and the standard values were above 0.7 , showing that the scale used in this paper can reliably measure the latent variables and the reliability of the questionnaire is guaranteed. The values for the Average Variation Extraction (AVE) of PE, PBC, SN, ATT, BI were, respectively, 0.582, 0.536, $0.608,0.743,0.739$, and 0.689 , which, being above 0.5 , are in line with the criteria recommended by Anderson, indicating that the relevant indicators can explain most of the variation of latent variables and prove to have good convergence validity [39]; see Table 3 [39].

Table 3. Results of confirmatory factor analysis.

\begin{tabular}{|c|c|c|c|c|c|c|c|}
\hline Variable & Item & Factor Loading & SMC & Cronbach's $\alpha$ & $t$ & CR & AVE \\
\hline \multirow{6}{*}{ Place emotion (PE) } & PE1 & 0.669 & 0.447 & \multirow[t]{6}{*}{0.889} & - & \multirow[t]{6}{*}{0.892} & \multirow[t]{6}{*}{0.582} \\
\hline & PE2 & 0.682 & 0.465 & & 15.692 & & \\
\hline & PE3 & 0.694 & 0.482 & & 15.944 & & \\
\hline & PE4 & 0.806 & 0.650 & & 18.114 & & \\
\hline & PE5 & 0.819 & 0.671 & & 18.352 & & \\
\hline & PE6 & 0.882 & 0.777 & & 19.394 & & \\
\hline \multirow{3}{*}{$\begin{array}{l}\text { Perceived behavioral } \\
\text { control }(\mathrm{PBC})\end{array}$} & PBC1 & 0.637 & 0.406 & \multirow[t]{3}{*}{0.812} & - & \multirow[t]{3}{*}{0.820} & \multirow[t]{3}{*}{0.536} \\
\hline & PBC2 & 0.802 & 0.644 & & 15.546 & & \\
\hline & PBC3 & 0.665 & 0.442 & & 13.784 & & \\
\hline \multirow{4}{*}{ Subjective norm (SN) } & SN1 & 0.807 & 0.651 & \multirow{4}{*}{0.818} & 15.580 & \multirow{4}{*}{0.822} & \multirow{4}{*}{0.608} \\
\hline & SN1 & 0.661 & 0.437 & & - & & \\
\hline & SN1 & 0.825 & 0.681 & & 16.28 & & \\
\hline & SN1 & 0.841 & 0.707 & & 16.229 & & \\
\hline \multirow{4}{*}{ Attitude (ATT) } & ATT1 & 0.865 & 0.748 & \multirow[t]{4}{*}{0.916} & - & \multirow[t]{4}{*}{0.920} & \multirow[t]{4}{*}{0.743} \\
\hline & ATT2 & 0.926 & 0.858 & & 33.675 & & \\
\hline & ATT3 & 0.914 & 0.836 & & 32.946 & & \\
\hline & ATT4 & 0.729 & 0.532 & & 22.338 & & \\
\hline \multirow{3}{*}{ Behavioral intention (BI) } & BI1 & 0.803 & 0.644 & \multirow[t]{3}{*}{0.861} & - & \multirow[t]{3}{*}{0.867} & \multirow[t]{3}{*}{0.689} \\
\hline & $\mathrm{BI} 2$ & 0.959 & 0.919 & & 22.756 & & \\
\hline & $\mathrm{BI} 3$ & 0.709 & 0.503 & & 19.828 & & \\
\hline
\end{tabular}

Note: $\mathrm{t}$ means $t$-test, SMC means Squared Multiple Correlation, CR means Composite Reliability, AVE means Average Variance Extracted. 
The test of discriminant validity was based on Fornell of the comparison of the AVE with the square of the variable correlation coefficient. If the AVE value is greater than the square of the variable correlation coefficient, there is good discriminant validity between variables [40]. It can be seen that the above results are in accordance with the verification standard proposed by Fornell. The correlation coefficient matrix is shown in Table 4.

Table 4. Analysis of Average Variation Extraction (AVE) discriminant validity.

\begin{tabular}{cccccc}
\hline Variable & PE & PBC & SN & ATT. & BI \\
\hline Place emotion (PE) & 0.582 & & & & \\
Perceived behavioral control (PBC) & 0.135 & 0.536 & & & \\
Subjective norm (SN) & 0.576 & 0.177 & 0.608 & & \\
Attitude (ATT.) & 0.539 & 0.138 & 0.392 & 0.743 & \\
Behavioral intention (BI) & 0.565 & 0.187 & 0.396 & 0.551 & 0.689 \\
\hline
\end{tabular}

Note: The triangle is the square of the Pearson correlation coefficient of the variable, and the diagonal is the AVE value.

\subsection{Structural Model and Parameter Estimation}

\subsubsection{Analysis of Model Fit}

After testing the reliability and validity of the measurement model, we conducted a path test of the structural model with the addition of SEM. From Table 3, it can be seen that the fit index of the modified model met all requirements except $\chi^{2} / \mathrm{df}$ (degrees of freedom), which was better than the initial model.

The model's fitness index was based on the absolute fit index, the incremental fit index, and the parsimonious fit index. In the absolute fit index, $\chi^{2} / \mathrm{df}=2.462$ was less than the accepted value of 3, GFI (Goodness of Fit Index) $=0.923$ fit the suggested value (GFI > 0.9), AGFI (Adjusted Goodness of Fit Index) $=0.898$ fit the suggested value (AGFI > 0.8), and the Root-Mean-Square Error of Approximation (RMSEA) was 0.061, less than the accepted value of 0.08. Among the incremental fit index, the standard fit index NFI (Normed Fit Index) $=0.938$ and RFI (Relative Fit Index) $=0.926$, while the non-standard fit index NNFI (Non-Normed Fit Index) $=0.946$ and IFI (Incremental Fit Index $)=0.955$, the Comparative Fit Index $(\mathrm{CFI})$ is 0.955 , greater than the accepted value of 0.9. In the parsimonious fit index, PNFI (parsimony-adjusted NFI) $=0.790$ and PGFI (parsimony-adjusted GFI) $=0.804$, which are both greater than the accepted value of 0.5 . We can conclude that the constructed model is acceptable. See Table 5 for more information.

Table 5. Revised fitness index.

\begin{tabular}{cccccccccccc}
\hline Index & $\boldsymbol{\chi}^{\mathbf{2}} / \mathbf{d f}$ & GFI & RMSEA & AGFI & NFI & NNFI & RFI & CFI & IFI & PNFI & PGFI \\
\hline Accepted value & $<3$ & $>0.9$ & $<0.08$ & $>0.8$ & $>0.9$ & $>0.9$ & $>0.9$ & $>0.9$ & $>0.9$ & $>0.5$ & $>0.5$ \\
Original model & 5.352 & 0.795 & 0.095 & 0.713 & 0.741 & 0.773 & 0.708 & 0.798 & 0.819 & 0.659 & 0.558 \\
Modified model & 2.462 & 0.923 & 0.061 & 0.898 & 0.938 & 0.946 & 0.926 & 0.955 & 0.955 & 0.790 & 0.804 \\
\hline
\end{tabular}

df: degree of freedom; GFI: Goodness of Fit Index; RMSEA: Root Mean Square Error of Approximation; AGFI: Adjusted Goodness of Fit Index; NFI: Normed Fit Index; NNFI: Non-Normed Fit Index; RFI: Relative Fit Index; CFI: Comparative Fit Index; IFI: Incremental Fit Index; PNFI: parsimony-adjusted NFI; PGFI: parsimony-adjusted GFI.

\subsubsection{Test of Structural Model}

As seen from Figure 2, local emotion had a positive influence on tourism attitude ( $\beta=0.598$, $t=9.727, p<0.001)$ and behavioral intention $(\beta=0.523, t=8.891, p<0.001)$, supporting H1a and H1b. Perceptual behavioral control had a positive influence on tourism attitude $(B=0.096, t=2.653, p<0.01)$ and behavioral intention ( $(B=0.082, t=2.681, p<0.05)$, supporting $\mathrm{H} 2 \mathrm{a}$ and $\mathrm{H} 2 \mathrm{~b}$. Subjective norm had a positive influence on tourism attitude $(B=0.132, t=2.238, p<0.05)$ and behavioral intention $(B=0.101, t=4.032, p<0.001)$, supporting H3a and H3b. Tourist attitude had a positive influence on behavioral intention $(\beta=0.203, t=4.935, p<0.001)$, supporting H4. The results are shown in Table 6 . 


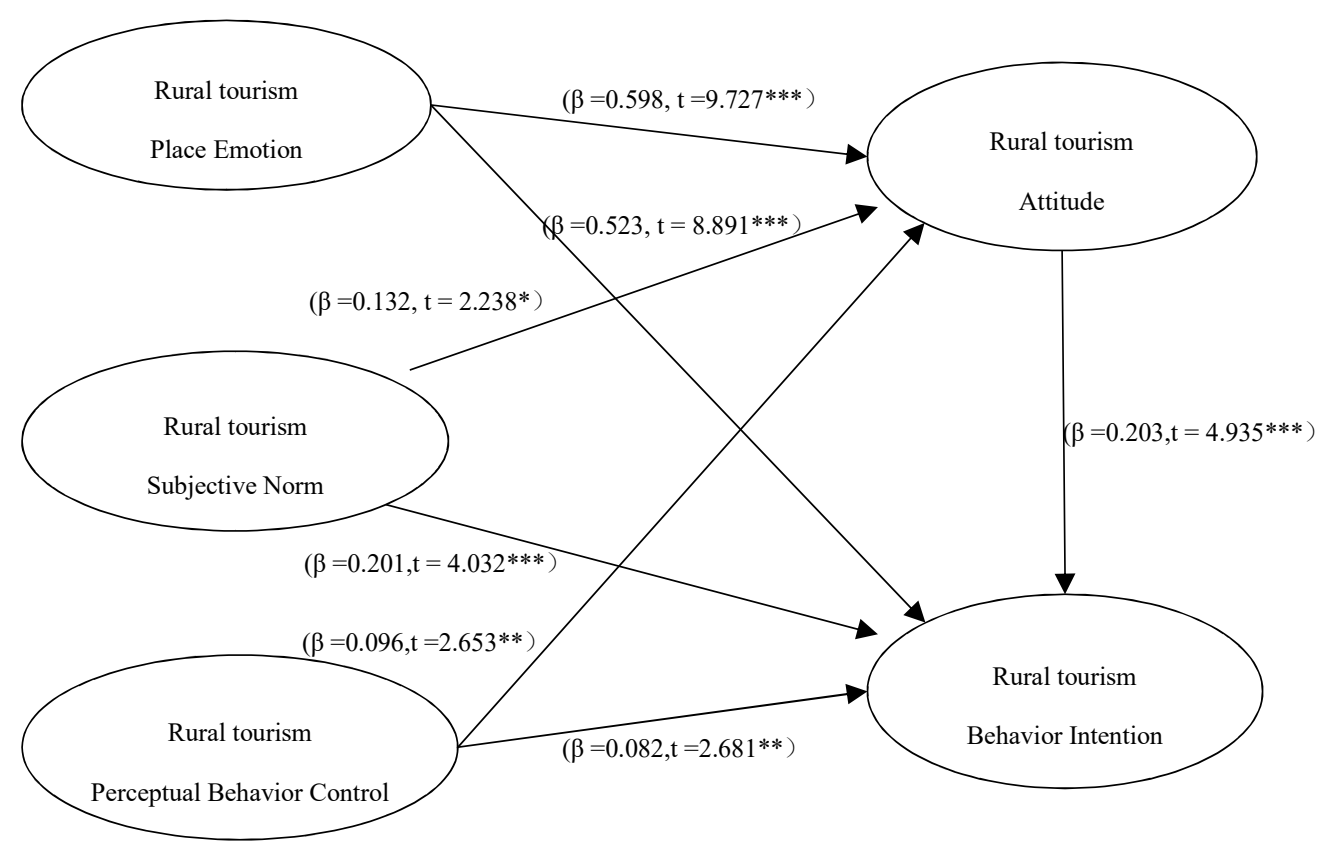

Figure 2. Structural model.

Table 6. Path analysis of Structural Equation Modeling (SEM).

\begin{tabular}{ccccc}
\hline Hypothetical Path Relationship & Standardized Path Coefficient & $\boldsymbol{t}$ & $\boldsymbol{p}$ & Result \\
\hline H1a: $\mathrm{PE} \rightarrow$ ATT & 0.598 & 9.727 & $* * *$ & Supported \\
H1b: PE $\rightarrow$ BI & 0.523 & 8.891 & $* * *$ & Supported \\
H2a: PBC $\rightarrow$ ATT & 0.096 & 2.653 & 0.008 & Supported \\
H2b: $\mathrm{PBC} \rightarrow$ BI & 0.082 & 2.681 & 0.007 & Supported \\
H3a: SN $\rightarrow$ ATT & 0.132 & 2.238 & 0.025 & Supported \\
H3b: SN $\rightarrow$ BI & 0.201 & 4.032 & $* * *$ & Supported \\
H4: ATT $\rightarrow$ BI & 0.203 & 4.935 & $* * *$ & Supported \\
\hline
\end{tabular}

Note: ${ }^{* * *} p<0.001$.

\subsubsection{Model Analysis}

We determined the goodness of fit of the rural tourist behavior intention model. The stability of the model was tested by loose and rigorous double checking. The difference of the chi-square value (MMF) between loose and rigorous was less than the difference of the degree of freedom multiplied by $3.84\left(\chi_{(1,0.05)}^{2}=3.84\right)$, indicating that the model was stable [41]. As shown in Table 7, the constructed rural tourist behavior intention model was in accordance with the mentioned criteria and was stable.

Table 7. Cross-validation of structural models.

\begin{tabular}{cccc}
\hline & \multicolumn{3}{c}{ Standard Validity Sample $\Delta$ MFF } \\
\cline { 2 - 4 } & Standard & MFF $\chi^{\mathbf{2}}(\mathbf{d f})$ & $\Delta$ MFF $\chi^{2}<(\Delta \mathbf{d f} \times \mathbf{3 . 8 4})$ \\
\hline \multirow{2}{*}{ Model } & $\begin{array}{c}\text { Unconstrained } \\
\text { Constrained }\end{array}$ & $265.54(249)$ & Yes \\
& $275.96(268)$ & $10.42<(13 \times 3.84=72.96)$ \\
\hline
\end{tabular}

MFF: minimum fit function; df: degree of freedom.

\subsection{Mediator Analysis}

The BK (Baron and Kenny's Approach) method and the Sobel Z test are the most common methods for testing mediation effects [42]; however, these are more and more oppugned to the two methods recently [43-45]. On the one hand, when using the BK method for path effect analysis, $\mathrm{a}$ and $\mathrm{b}$ were significant; however, $\mathrm{a}^{*} \mathrm{~b}$ was not necessarily significant and tended to reveal abnormal 
distribution $[46,47]$. On the other hand, the Sobel $\mathrm{Z}$ test had insufficient verification power, especially in estimating indirect effects [47]. Taylor [48], Hayes [43], and MacKinnon [49] suggested that when testing the significance of the mediator, the bootstrapping method should be used. That method uses the editing syntax to calculate multiple mediators without considering whether to violate the assumption of normal distribution.

When using the SEM to analyze the mediator, the most important step is to use the bootstrap to find the confidence interval of the indirect effect. If the confidence interval is not zero, it means that there is an intermediary effect [48]. However, Cheung and Lau (2008) and Lau and Cheung (2012) respectively proposed a judgment on the effect of mediation for the analysis of mediation effects. They adopted that the Confidence Interval (CI) is $(1-\alpha) 100 \%$; usually, setting $95 \%$ CI does not consist of zero, that is, it is statistically significant at the significance level of $\alpha$.

This study used the bootstrap self-sampling method of Amos 21.0. In the original data $(\mathrm{N}=650)$, the samples were randomly examined 5000 times and the error correction confidence interval was set to $95 \%$. The results in Table 8 show that local emotions, perceptual behavioral control, and subjective norms with attitudes on behavioral intentions, pass the $\mathrm{CI}$ of the indirect effects of attitudes, regardless of the percentage confidence interval (Percentile CI) in the $95 \%$ confidence interval. The bias value confidence interval (Bias CI) did not contain 0 , and is significant, thus it can be determined that the indirect effect was significant. Moreover, the confidence interval of the direct effect of local emotion, perceptual behavior control, and subjective norms on the three modes of behavioral intention did not include 0 , and was significant, indicating that direct effects exist. From the above analysis, it can be seen that attitudes have a partial mediating effect on space emotions, perceptual behavior control, and subjective norms to behavioral intentions, and thus, $\mathrm{H} 5 \mathrm{a}, \mathrm{H} 5 \mathrm{~b}$, and $\mathrm{H} 5 \mathrm{c}$ are supported.

Table 8. Analysis of structural model.

\begin{tabular}{|c|c|c|c|c|c|c|c|c|}
\hline \multirow{3}{*}{ Path } & \multirow{3}{*}{ Point Estimation } & & & \multicolumn{4}{|c|}{ Bootstrapping 5000 Times } & \multirow[b]{3}{*}{$p$} \\
\hline & & & & \multicolumn{2}{|c|}{ Bias-Corrected $95 \%$ CI } & \multicolumn{2}{|c|}{ Percentile $95 \% \mathrm{CI}$} & \\
\hline & & SE & $\mathrm{Z}$ & Lower & Upper & Lower & Upper & \\
\hline \multicolumn{9}{|c|}{ Indirect effect } \\
\hline $\mathrm{PE} \rightarrow \mathrm{ATT} \rightarrow \mathrm{BI}$ & 0.164 & 0.044 & 3.727 & 0.089 & 0.265 & 0.083 & 0.257 & $* * *$ \\
\hline $\mathrm{PBC} \rightarrow \mathrm{ATT} \rightarrow \mathrm{BI}$ & 0.024 & 0.012 & 2.000 & 0.004 & 0.052 & 0.001 & 0.047 & 0.022 \\
\hline $\mathrm{SN} \rightarrow \mathrm{ATT} \rightarrow \mathrm{BI}$ & 0.036 & 0.022 & 1.636 & 0.003 & 0.087 & 0.003 & 0.086 & 0.024 \\
\hline Total indirect effect & 0.224 & 0.057 & 3.930 & 0.121 & 0.347 & 0.425 & 0.814 & $* * *$ \\
\hline \multicolumn{9}{|c|}{ Direct effect } \\
\hline $\mathrm{PE} \rightarrow \mathrm{BI}$ & 0.615 & 0.099 & 6.212 & 0.426 & 0.814 & 0.005 & 0.175 & $* * *$ \\
\hline $\mathrm{PBC} \rightarrow \mathrm{BI}$ & 0.085 & 0.043 & 1.977 & 0.002 & 0.169 & 0.053 & 0.360 & 0.047 \\
\hline $\mathrm{SN} \rightarrow \mathrm{BI}$ & 0.214 & 0.078 & 2.744 & 0.057 & 0.361 & 0.118 & 0.343 & 0.006 \\
\hline Total direct effect & 1.137 & 0.067 & 16.970 & 1.012 & 1.272 & 1.015 & 1.274 & $* * *$ \\
\hline Total effect & 1.361 & 0.086 & 15.826 & 1.200 & 1.540 & 1.199 & 1.538 & $* * *$ \\
\hline \multicolumn{9}{|c|}{ Comparison of mediation effect } \\
\hline$(\mathrm{PE}-\mathrm{PBC}) \rightarrow \mathrm{ATT} \rightarrow \mathrm{BI}$ & 0.140 & 0.043 & 3.256 & 0.070 & 0.241 & 0.065 & 0.233 & $* * *$ \\
\hline$(\mathrm{PE}-\mathrm{SN}) \rightarrow \mathrm{ATT} \rightarrow \mathrm{BI}$ & 0.128 & 0.043 & 2.977 & 0.060 & 0.237 & 0.053 & 0.22 & $* * *$ \\
\hline$(\mathrm{PBC}-\mathrm{SN}) \rightarrow \mathrm{ATT} \rightarrow \mathrm{BI}$ & -0.013 & 0.026 & -0.500 & -0.071 & 0.033 & -0.072 & 0.032 & 0.589 \\
\hline
\end{tabular}

Note: ${ }^{* * *} p<0.001$.

This paper compared the indirect mediation effect of attitudes to behavioral intention among space emotions, perceptual behavior control, and subjective norms. It can be seen from the comparison that the indirect effects of space emotions were the largest, followed by those of subjective norms and perceptual behavioral control. Among them, the space emotion and perceptual behavioral control, the indirect intermediation effect of local emotion and subjective norm were significantly different. Meanwhile, the indirect mediation effect of perceptual behavior control and subjective norm was not significant. 


\section{Conclusions}

The explanation and predicted goodness of fit index of the constructed model for rural space emotional tourism intention were good and the model has the stability of reviewing effect. It can be seen from the model of rural tourists that the explanatory power of behavioral intention was 0.785 , and that space emotion had the most significant effect on behavioral intentions, followed by attitude, subjective norm, and perceptual behavior control. Tourists' intention effect on selecting the tourism destination had different influence trends.

The results of this study were not only good for understanding the relationship between rural tourist intention and actual behavior, but also allowed an interpretation of the shortcomings of some scholars on the TPB, after adding space emotion between them. When tourists with space emotions engage in rural tourism activities, space emotions had a stronger effect on the behavioral intention than the perceptual behavior control factors. It was more standardized and detailed for the measurement of behavioral intention and also presented the expected views in the final study. Additionally, remodeling the attitude in the model improved the explanation and prediction of the final model.

There exists a specific value of human-land relationship in Chinese rural tourism destinations [50]; hence, tourists will form a positive emotional linked with the tourist destinations, which will result in the emotional attachment of tourists. The tourists had more positive emotion towards rural tourism destinations; the greater the possibility of these behaviors (such as consumer behavior, re-visit, and word-of-mouth behavior), is the more favorable for the development of rural tourism destinations.

In the context of China's rural tourism development, rural tourism, as an important means to promote rural revitalization, has gained unanimous consensus between the academic and the industry. On the other hand, with the transformation of the basic paradigm of human-land relationship research from the initial geography to the combination of geography and sociological micro-individual subjective experience, tourists' emotions about rural areas have become an important topic in human geography. Under the trend of this "emotional turn", geographers began to explore the inner mechanism of research upon emotional geography [51]. The emotional process generated by this mechanism can be summarized as: space emotions are a complex mechanism influencing tourists' choice of rural tourism destinations. If people find that they have positive emotions for a certain destination, the number of tourists in this area is likely to increase [13]. Generally speaking, the "human-land emotional relationship" of rural tourists is a multi-dimensional interactive cross-relationship and structure. The conclusion of this study lays a theoretical framework for the other scholars to further study the driving mechanism of rural tourism behavior.

Space emotion has a significant positive effect on attitude and behavioral intention, as do perceptual behavioral control and subjective norm. It can be seen from the standardized path coefficient that the space emotion has the strongest effect on attitudes and behavioral intention, followed by subjective norms and perceptual behavioral control. Thus, it is necessary to expand the space emotion in this study.

Reconstructing the relationship among space emotion, perceptual behavior control, and subjective norm with attitude can improve the explanation of the model. This also verifies the opinion that the subjective norm and attitude are not independent predictors, but rather are interrelated. When operating rural tourism activities, operators will be affected by the opinions of relatives and friends, which not only affect the attitude to their behavior towards engaging in tourism activities, but also indirectly promote a willingness to engage in rural tourism activities. This significantly enhances the explanation of tourists' recreation behavior by remodeling the attitude relationship. Tourist behavioral intention is not only directly affected by positive behavioral attitude, although the subjective normative and perceptual behavioral controls are stronger; the tourist has a more positive attitude, and thus forms a positive intention to travel. 


\section{Discussion}

From the demographic analysis of the respondents in this study, we can realize that the rural tourists are mainly professional or educational staff, students, and staff from enterprises or institutions. Tourists who were participating in rural tourism for the first time accounted for $82.7 \%$ of respondents; these were mainly professional or educational staff, students, staff from enterprises or institutions, and civil servants. This discovery can help provide suggestions for developing rural tourism management. The amount of tourists who were participating in rural tourism for the first time represented a high proportion, indicating that there is still potential for developing rural tourist destinations. This also shows that the management of Xidi and Hongcun need to do something to stimulate tourists to revisit. Furthermore, after cross-overlap test of the statistical items, it is clear that there is a different composition of tourists in each market segment; therefore, the management can adjust their marketing strategy accordingly to these discoveries and promote the sustainable development of rural tourism.

The proportion of tourists staying in rural areas for one day is as high as $68.5 \%$, which provides further inspiration for rural operators to think about how to encourage tourists to stay more than one day. The core reason for short stays is that the tourist product is single. Expanding the type of rural tourism can connect with tourists and lead them to increase the duration of their holidays.

Attitude has a partial mediating effect on space emotion, perceptual behavioral control, and subjective norms on behavioral intentions of tourists. In other words, promoting local emotions, perceptual behavior control, and subjective norms can make tourists taking part in rural tourism more positive. It will take long time to develop space emotion. Space emotion, attitudes, perceptual behavioral control, and desire are all personal factors, while subjective norms are social factors. Both factors theoretically affect the behavioral intentions of tourists. Promoting the space emotion is particularly critical; that is, the insatiable demand of tourists caused by space emotion, the increasing demand for basic travel experiences that can stimulate tourists' emotions, and the enhancing effect that encouragement from relatives and friends has on engagement in rural tourism can all raise the interest of tourists in rural tourism experiences.

In the process of developing rural tourism, tourism practitioners and government relative departments should focus on space emotions, propose factors that tourists care about, whether or not they can meet their emotional needs, pay attention to the core elements of rural tourism products, and raise awareness of rural ecological environment and culture. Specifically, we can start from the emotional connection that tourists have with the rural environment to attract rural tourists with high space emotions by designing landscape symbols, facility decoration, special products, and interactive section that can provoke the tourists' memories and imaginations to the countryside, lead them to participate in rural tourism and leisure activities, and further promote the emotional attachment of tourists to the rural environment, thus increasing the importance of rural tourism destinations. At the same time, since high local emotions are more concerned about rural tourism than ordinary tourists, and a comfortable rural tourism experience also implies that tourists will be more likely to travel to another country. Therefore, local management departments should make good use of the impact of space emotions, conduct marketing research, extract the cultural symbols of various rural tourists and their specific-image design, and create advertisement that can resonate with tourists. The marketing of rural destinations can achieve good results with half the effort.

Space emotions have a strong influence on the behavioral intentions of rural tourists; thus, tourists will put rural tourism as the first choice when they have a willingness to travel. In order to obtain emotional satisfaction in a tourist destination, it is necessary for the local residents of the tourist destination to participate in the tourism activities and in the operation, provide comments, and give vivid scenes, which also helps to restore the original rural atmosphere and meet the tourists' expectation of the authenticity of the destination (e.g., a village). Likewise, this can improve the satisfaction of the tourist experience. Additionally, tourism practitioners and tourism management departments should take a responsible attitude to protect the environment and local culture as a 
development goal. Developing rural tourism without destroying the environment is the only way to ensure the integrity of local resources, meet rural tourist demand, and develop rural tourism.

The rapid development of rural tourism will bring out the decline of rural environmental quality, the damage of rural culture, the homogenous competition among tourism, the low overall quality, the insufficient of industry training, the shortage of capital or human resource, the backward of operation mode, and the dislocation of land use. At the same time, the development of rural tourism is an important way to break the urban-rural dual structure, promote rural transformation and development, and increase the income and employment of farmers. It is also an important indicator to effectively meet the needs of the tourism market and improve the level of tourism development. Therefore, it is necessary to reflect on the development of rural tourism, we should guide rural tourism to break through the dilemma by deepening theoretical research and strengthening practical application. Theoretical breakthroughs and academic innovations are needed that focus on finding a match point among rural tourism and rural ecological civilization on the one hand and rural beautiful constructions that make the countryside a suitable habitat for tourism and leisure places on the other.

In summary, rural tourism must involve co-operation by local residents, government authorities, tourists, and tourism companies. The operators and managers recognize that a good rural environment is closely related to the choice of tourists, and make specific efforts for the environment. Rural tourist locations will become popular tourist destinations and achieve sustainable development. Against the background of rural tourism as a strategy of rural vitalization, we need more empirical research to improve the research model and then to propose suggestions about contributing to the sustainable development of rural tourism.

Author Contributions: Conceptualization, L.W. and Y.Z.; methodology, Y.Z.; software, Y.Z.; validation, Y.Z.; formal analysis, Y.Z.; investigation, L.W.; resources, Y.Z.; data curation, L.W.; writing—original draft preparation, Y.Z.; writing—review and editing, L.W.; visualization, L.W.; supervision, Y.Z.; project administration, Y.Z.; funding acquisition, Y.Z.

Funding: This research was funded by the Anhui Philosophy and Social Science Planning Project, Grand No. AHSKY2018D23 and The APC was funded by Anhui Philosophy and Social Science Planning Project.

Conflicts of Interest: The author declares no conflict of interest.

\section{References}

1. Liu, Y. Research on the urban-rural integration and rural revitalization in the new era in China. Acta Geogr. Sin. 2018, 73, 637-650.

2. Long, H.; Zhang, Y.; Tu, S. Land consolidation and rural vitalization. Acta Geogr. Sin. 2018, 73, $1837-1849$. [CrossRef]

3. He, R. Urban-rural integration and rural revitalization: Theory, mechanism and implementation. Geogr. Res. 2018, 37, 2127-2140.

4. Huang, Z.; Huang, R. Research progress on rural culture in the context of rapid urbanization and tourism development: Academic debate and future research prospects. Geogr. Res. 2018, 37, 233-249.

5. Cheng, J.; Zhang, L.; Yang, X.; Li, G. The impact of tourism development on changes of households' livelihood and community tourism effect: A case study based on the perspective of tourism development mode. Geogr. Res. 2017, 36, 1709-1724.

6. Wu, J.; Zhou, C.; Xie, W. The Influencing Factors and Evaluation of Farmer's Adaptability Towards Rural Tourism in Traditional Village: Based on the Survey of 6 Villages in Xiangxi Prefecture, Hunan. Sci. Geogr. Sin. 2018, 38, 755-763. [CrossRef]

7. Devesa, M.; Laguna, M.; Palacios, A. The role of motivation in visitor satisfaction. Empirical evidence in rural tourism. Tour. Manag. 2010, 31, 547-552. [CrossRef]

8. $\mathrm{Su}, \mathrm{L} . ;$ Huang, F. A study on the relationships of service fairness, consumption emotions and tourist loyalty: A case study of rural tourists. Geogr. Res. 2010, 30, 463-476. [CrossRef]

9. Rid, W.; Ezeuduji, I.O.; Pröbstl-Haider, U. Segmentation by motivation for rural tourism activities in The Gambia. Tour. Manag. 2014, 40, 102-116. [CrossRef] 
10. Yang, X.; Li, J. Analysis of the Composition of Rural Ecotourists: A Case Study of Agro-tourism in Shangwang Village of Xi'an. J. Yunnan Norm. Univ. Humanit. Soc. Sci. 2013, 45, 25-32.

11. Han, H. Travelers' pro-environmental behavior in a green lodging context. Converging value-belief-norm theory and the theory of planned behavior. Tour. Manag. 2015, 47, 164-177. [CrossRef]

12. Ji, C.; Nie, Y. Chinese Tourists' Gaming Consumer Behavioral Intent and Its Influencing Factors: An Empirical Test Based on MGB Theory. Tour. Trib. 2017, 32, 37-46.

13. Zhang, Y.; Yu, X.; Cheng, J.; Chen, X.; Liu, T. Recreational behavior and intention of tourists to rural scenic spots based on TPB and TSR Models. Geogr. Res. 2017, 36, 1725-1741.

14. Lin, J.; Wu, C.; Liu, W.-Y.; Lee, C.-C. Behavioral intentions toward afforestation and carbon reduction by the Taiwanese public. For. Policy Econ. 2012, 14, 119-126. [CrossRef]

15. Sparks, B.; Pan, G.W. Chinese Outbound tourists. Understanding their attitudes, constraints and use of information sources. Tour. Manag. 2009, 30, 483-494. [CrossRef]

16. Ajzen, I.; Driver, B.L. Driver. Prediction of leisure participation from behavioral, normative, and control beliefs: An application of the theory of planned behavior. Leis. Sci. 1991, 13, 185-204. [CrossRef]

17. Qiong, D.; Zhao, H. A Study on the Tourist Destination Choice Model Constructed on the Base of Place Emotion. Tour. Trib. 2016, 31, 105-112.

18. Zhou, L.; Li, Q.; Zhu, L. Outcome Efficacy, People-destination Affect, and Tourists' Environmentally Responsible Behavior Intention: A Revised Model Based on the Theory of Planned Behavior. J. Zhejiang Univ. Humanit. Sci. 2014, 44, 88-98.

19. Ramkissoon, H.; Weiler, B.; Smith, L.D. Place attachment and pro-environmental behaviour in national parks: The development of a conceptual framework. J. Sustain. Tour. 2012, 20, 257-276. [CrossRef]

20. Williams, D.R.; Vaske, J.J. The Measurement of Place Attachment. Validity and Generalizability of a Psychometric Approach. For. Sci. 2003, 49, 830-840.

21. Halpenny, E. Pro-environmental behaviours and park visitors. The effect of place attachment. J. Environ. Psychol. 2010, 30, 409-421. [CrossRef]

22. Cass, N.; Walker, G. Emotion and rationality. The characterization and evaluation of opposition to renewable energy projects. Emot. Space Soc. 2009, 2, 62-69. [CrossRef]

23. Chan, D.K.; Fishbein, M. Determinants of College Women's Intentions to Tell Their Partners to Use Condoms. J. Appl. Soc. Psychol. 1993, 23, 1455-1470. [CrossRef]

24. Ekinci, Y.; Sirakaya-Turk, E.; Preciado, S. Symbolic consumption of tourism destination brands. J. Bus. Res. 2013, 66, 711-718. [CrossRef]

25. Kyle, G.; Graefe, A.; Manning, R. Testing the Dimensionality of Place Attachment in Recreational Settings. Environ. Behav. 2005, 37, 153-177. [CrossRef]

26. Hung, K.; Petrick, J.F. Testing the effects of congruity, travel constraints, and self-efficacy on travel intentions: An alternative decision-making model. Tour. Manag. 2012, 33, 855-867. [CrossRef]

27. Han, H.; Hsu, L.-T.; Sheu, C. Application of the Theory of Planned Behavior to Green Hotel Choice. Testing the Effect of Environmental Friendly Activities. Tour. Manag. 2011, 31, 325-334. [CrossRef]

28. Ryu, K.; Jang, S. Intention to Experience Local Cuisine in a Travel Destination: The Modified Theory of Reasoned Action. J. Hosp. Tour. Res. 2006, 30, 507-516. [CrossRef]

29. Fielding, K.S.; McDonald, R.; Louis, W.R. Theory of planned behaviour, identity and intentions to engage in environmental activism. J. Environ. Psychol. 2008, 28, 318-326. [CrossRef]

30. Song, H.-J.; Lee, C.-K.; Norman, W.C.; Han, H. The Role of Responsible Gambling Strategy in Forming Behavioral Intention: An Application of a Model of Goal-Directed Behavior. J. Travel Res. 2012, 51, 512-523. [CrossRef]

31. Bagozzi, R. The Self-Regulation of Attitudes, Intentions, and Behavior. Soc. Psychol. Q. 1992, 55, $178-204$. [CrossRef]

32. Perugini, M.; Bagozzi, R.P. The role of desires and anticipated emotions in goal-directed behaviours: Broadening and deepening the theory of planned behaviour. Br. J. Soc. Psychol. 2001, 40, 79-98. [CrossRef] [PubMed]

33. Perugini, M.; Bagozzi, R.P. The distinction between desires and intentions. Eur. J. Soc. Psychol. 2004, 34, 69-84. [CrossRef] 
34. Lee, C.-K.; Song, H.-J.; Bendle, L.J.; Kim, M.-J.; Han, H. The impact of non-pharmaceutical interventions for 2009 H1N1 influenza on travel intentions: A model of goal-directed behavior. Tour. Manag. 2012, 33, 89-99. [CrossRef]

35. Fry, M.-L.; Drennan, J.; Previte, J.; White, A.; Tjondronegoro, D. The role of desire in understanding intentions to drink responsibly: An application of the Model of Goal-Directed Behaviour. J. Mark. Manag. 2014, 30, 551-570. [CrossRef]

36. Avolio, B.J.; Yammarino, F.J.; Bass, B.M. Identifying Common Methods Variance with Data Collected from A Single Source: An Unresolved Sticky Issue. J. Manag. 1991, 17, 571-587. [CrossRef]

37. Podsakoff, P.M.; MacKenzie, S.B.; Lee, J.-Y.; Podsakoff, N.P. Common method biases in behavioral research: A critical review of the literature and recommended remedies. J. Appl. Psychol. 2003, 88, 879-903. [CrossRef] [PubMed]

38. Kline, R.B. Methodology in the Social Sciences. Principles and Practice of Structural Equation Modeling, 4th ed.; Guilford Press: New York, NY, USA, 2015; ISBN 978-1462523344.

39. Anderson, J.; Gerbing, D.W. Structural Equation Modeling in Practice: A Review and Recommended Two-Step Approach. Psychol. Bull. 1988, 103, 411-423. [CrossRef]

40. Fornell, C.; Larcker, D. Evaluating Structural Equation Models with Unobservable Variables and Measurement Error. J. Mark. Res. 1981, 18, 39-50. [CrossRef]

41. MacKinnon, D.P.; Fairchild, A.J.; Fritz, M.S. Mediation analysis. Annu. Rev. Psychol. 2007, 58, 593-614. [CrossRef] [PubMed]

42. Hayes, A.F. Beyond Baron and Kenny: Statistical Mediation Analysis in the New Millennium. Commun. Monogr. 2009, 76, 408-420. [CrossRef]

43. Rucker, D.D.; Preacher, K.J.; Tormala, Z.L.; Petty, R.E. Mediation Analysis in Social Psychology: Current Practices and New Recommendations. Soc. Personal. Psychol. Compass 2011, 5, 359-371. [CrossRef]

44. Zhao, X.; Lynch, J.; Chen, Q. John Deighton served as editor and Gavan Fitzsimons served as associate editor for this article. Reconsidering Baron and Kenny: Myths and Truths about Mediation Analysis. J. Consum. Res. 2010, 37, 197-206. [CrossRef]

45. Lee, B.; Shafer, C.S.; Kang, I. Examining Relationships Among Perceptions of Self, Episode-Specific Evaluations, and Overall Satisfaction with a Leisure Activity. Leis. Sci. 2005, 27, 93-109. [CrossRef]

46. Preacher, K.J.; Hayes, A.F. SPSS and SAS procedures for estimating indirect effects in simple mediation models Behavior Research Methods. Instrum. Comput. 2004, 36, 717-731. [CrossRef]

47. Taylor, A.B.; MacKinnon, D.P.; Tein, J.-Y. Tests of the Three-Path Mediated Effect. Organ. Res. Methods 2008, 11, 241-269. [CrossRef]

48. MacKinnon, D.P.; Lockwood, C.M.; Hoffman, J.M.; West, S.G.; Sheets, V. A comparison of methods to test mediation and other intervening variable effects. Psychol. Methods 2002, 7, 83-104. [CrossRef] [PubMed]

49. Cheung, G.W.; Lau, R.S. Testing Mediation and Suppression Effects of Latent Variables: Bootstrapping with Structural Equation Models. Organ. Res. Methods 2008, 11, 296-325. [CrossRef]

50. Li, X.; Yang, Y.; Liu, Y. The evolution process and its mechanism of man-land relationship in China. Geogr. Res. 2018, 37, 1495-1514. [CrossRef]

51. Gao, Q.; Qian, J. Negotiating Place-Restructuring from The Perspective of Emotional Geographies: A Case Study of Liede Village, Guangzhou. Hum. Geogr. 2016, 31, 33-41. [CrossRef]

(C) 2019 by the authors. Licensee MDPI, Basel, Switzerland. This article is an open access article distributed under the terms and conditions of the Creative Commons Attribution (CC BY) license (http://creativecommons.org/licenses/by/4.0/). 